\title{
PreVEnTING SUDDEN INFANT DEATH SYNDROME IN NSW: IMPACT OF HEALTH EDUCATION CAMPAIGNS
}

\author{
Elisabeth Murphy, Acting Director, Clinical Policy \\ and Practice \\ Pam Adelson, Epidemiologist, Epidemiology Branch, \\ NSW Health Department
}

In 1992, the NSW Health Department and the Sudden Infant Death Association of NSW (SIDA) conducted Statewide health education campaigns aiming to reduce the incidence of Sudden Infant Death Syndrome (SIDS). The campaigns were based on mounting epidemiological evidence indicating that the prone sleeping position was a risk factor for SIDS ${ }^{1,23,4,5}$ and were supported by National Health \& Medical Research Council recommendations that infants should generally be placed to sleep in the supine position or on their sides $^{6}$. This report outlines the results of surveys carried out before and after the campaigns to assess their impact.

The Department's campaign was directed at health professionals, and included seminars and distribution of a circular detailing Departmental policy $^{7}$. The SIDA campaign targeted the general community through television advertisements which went to air at peak viewing times.

The campaigns:

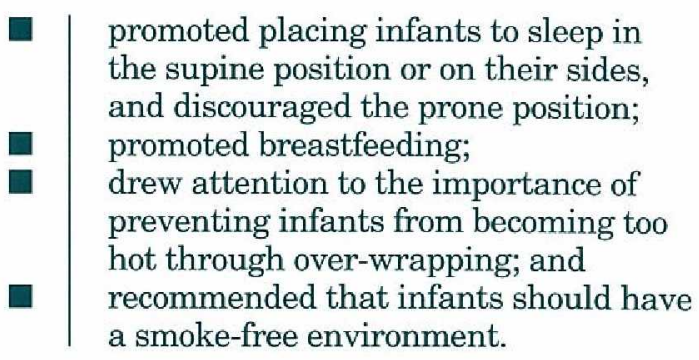

To determine whether these campaigns influenced parental behaviour, the Department conducted two surveys, in 1991 and 1992 (before and after the campaigns respectively).

The surveys were done in Early Childhood Health Centres (ECHCs) in the former New England Region of NSW and in the Northern Sydney, South Western Sydney and Illawarra Health Areas. Sequential samples of parents attending the ECHCs were given a short self-administered questionnaire which sought information on the infant's age and sex, the language spoken in the home and the smoking status of household members. The respondent was asked in what position the infant was usually placed to sleep (on the back, on the stomach, or on the side).

One hundred questionnaires were sent to the ECHCs in the New England Region and each of the three Areas before the campaigns in 1991, and a second 100 in 1992. The number of questionnaires distributed to each $\mathrm{ECHC}$ was proportional to the catchment population.

A total of 367 parents completed questionnaires in 1991 (representing a 92 per cent response rate), and 437 questionnaires were returned in 1992 (additional copies were produced in and returned from the Illawarra Area). Only questionnaires referring to infants aged 3-6 months were included in this analysis (67 per cent of questionnaires distributed in 1991, and 63 per cent in 1992). Data were analysed using the Statistical Analysis System.

In the 1991 survey, 21 per cent of parents of infants aged 3-6 months reported that they placed their infants to sleep in the prone position. In the 1992 survey, the figure was 6 per cent $(p<0.001)$.

The change in the breastfeeding prevalence was not significant; 62 per cent of parents in 1991 and 59 per cent in 1992 reported that their infants were breastfed. The change in the proportion of homes where a household member smoked was also nonsignificant ( 30 per cent in 1991, and 25 per cent in 1992).

Elsewhere in this issue Guevarra and Taylor report a substantial decrease in the incidence of SIDS since 1990 , when the rate was 2.1 per 1,000 livebirths; rates in 1991 and 1992 were 1.5 and 1.2 per 1,000 livebirths respectively. This decrease paralleled campaigns promoting parental behaviour associated with a low risk of SIDS. The results presented here suggest the desired change in behaviour also paralleled the campaigns. This provides circumstantial evidence that the campaigns led to improved health outcomes, i.e. a reduction in the incidence of SIDS.

\footnotetext{
1. Guntheroth WG, Spiers PS. Sleeping prone and the risk of sudden infant death syndrome. JAMA 1992; 267 (17):2359-2362. 2. Mitchell EA, Ford RPK, Stewart DMO et al. Further evidence supporting a causal relationship between prone sleeping position and SIDS. J Paediatr Child Health 1992; 28:S9-12.

3 . Ponsonby AL, Dwyer T, Gibbons LE et al. Factors potentiating the risk of sudden infant death syndrome associated with the prone position. N Engl J Med 1993; 329(6):377-382.

4. Mitchell EA, Taylor BJ, Ford RPK et al. Four modifiable and other major risk factors for cot death: the New Zealand study. $J$ Paediatr Child Health 1992; 28:S3-8.

5. Dwyer T, Ponsonby ALB, Newman NM, Gibbons LE. Prospective cohort study of prone sleeping position and sudden infant death syndrome. Lancet 1991; 337:1244-7.

6. NHMRC Publication CM No. 27 Risk Factors Associated with Sudden Infant Death Syndrome (SIDS) (October 1991) (Pamphlet). 7. NSW Health Department. Sudden Infant Death Syndrome and Associated Risk Factors Information Bulletin No. 91/44 11 September 1991.

8. Guevarra V, Taylor L. Sudden infant death syndrome in NSW, 1992. NSW Public Health Bulletin 1994; 5(8):85-86.
} 